\title{
Itching and rashes on contact with latex among patients attending community contraceptive clinics
}

\author{
Elspeth Hamilton
}

\section{Background}

Itching following contact with latex condoms is a familiar problem in contraceptive services, and popular textbooks still maintain that it is frequently an excuse for avoiding condoms, or that spermicide is to blame. ${ }^{1}$ If a patient experiences symptoms on contact with other latex items as well as condoms then it would be reasonable to suspect sensitivity to something in the rubber material, either natural rubber latex (NRL) or accelerator chemicals used to convert liquid latex into solid rubber.

'Latex allergy' is a loose term applied to allergic reactions following contact with rubber material used to make condoms, surgical gloves, etc. Reactions fall into two groups: Type I immediate hypersensitivity to NRL protein, causing a range of symptoms from transient urticaria and sneezing to coughing, wheezing and full-blown anaphylaxis; and Type IV delayed hypersensitivity response causing prolonged dermatitis. Type IV reactions are usually due to accelerator chemicals rather than NRL. ${ }^{2}$

Latex allergy gained notoriety in the late 1980s following a series of fatal anaphylactic reactions during barium enemas in the USA. The Health \& Safety Executive (HSE) issued recommendations, ${ }^{3}$ however serious anaphylactic reactions continued to occur in patients with known Type I NRL allergy because staff were not aware of hidden latex in drugs and equipment. In 2004 a survey by the National Patient Safety Agency revealed that $40 \%$ of NHS Trusts still did not have operational latex policies. ${ }^{4}$ In order to address this, the HSE published a toolkit to identify symptoms suggesting NRL allergy in patients about to have surgery, and new employees required to wear latex gloves. 5 The toolkit highlights the importance of a history of itching and rashes following contact with latex gloves, condoms and balloons, and advises that affected individuals should not have further contact with latex until this has been investigated. The risk of developing Type I NRL allergy is increased by frequent contact with latex through occupation or medical treatment, atopic tendencies, and allergy to foods that share common allergens with NRL protein (e.g. kiwi, banana, avocado, raw potato, chestnuts).

\section{Study method}

The author conducted a 4-year observational study of all her patients in community contraceptive clinics, asking them directly whether they experienced itching or rashes on contact with latex condoms, gloves or balloons, instead of just asking "Are you allergic to latex?". Patients who already had a diagnosis of 'latex allergy' were not questioned further. The Trust's Latex Allergy Checklist (using key points from the HSE toolkit) was only completed for those individuals with undiagnosed itching and rashes. Their details were recorded in a manual log and

J Fam Plann Reprod Health Care 2008; 34(2): 129-130

Gwent Healthcare National Health Service Trust, Department of Community Gynaecology and Sexual Health, Cwmbran, UK Elspeth Hamilton, MBBCh, Staff Grade Doctor

Correspondence to: Dr Elspeth Hamilton, Gwent Healthcare NHS Trust, Department of Community Gynaecology and Sexual Health, Llanyrafon House, Llanfrechfa Grange, Cwmbran, Torfaen NP44 8YN, UK. E-mail: elspeth.hamilton@gwent.wales.nhs.uk the outcomes of referrals were collated at the end of the study. The total number of patients seen and their demographics were derived from computerised clinic records.

\section{Results}

A total of 2146 patients were seen, but 4\% (89/2146) had incomplete records and could not be traced. 2057 records were analysed; $98.6 \%$ were female and $1.4 \%$ male. Patients were aged between 12 and 80 years, with $50 \%$ between the late teens and mid-thirties. 3.9\% (83/2146) said either they or their partner had itching on contact with latex condoms or gloves. $7 / 83(8.4 \%)$ said they had already been given a formal diagnosis of 'latex allergy'. This represented $0.3 \%$ of the total clinic population. 10/83 (12\%) said their partner could not tolerate latex, leaving 66 patients to be screened with the checklist. This was only $3.1 \%(66 / 2146)$ of the total patients seen.

A few patients $(6.1 \%, 4 / 66)$ described condoms causing soreness or burning rather than itching, and had not reacted to any other rubber/latex items and did not have any known risk factors for developing Type I NRL allergy. They were given the Trust's patient information leaflet on latex allergy and advised to return for referral if their symptoms worsened. Two $(3.0 \%)$ patients declined to discuss the checklist.

Most (91\%, 60/66) patients had symptoms for which dermatology referral was recommended by the Trust's Latex Policy. 56\% of them had reacted to two or more rubber/latex items and $73 \%$ of them had at least one risk factor for developing Type I NRL allergy, but only $13 \%(8 / 60)$ actually attended dermatology for diagnostic testing.

Half (4/8) of those who attended dermatology were advised to avoid future contact with latex. Only one person had Type I NRL allergy, but three others had multiple risk factors for developing it including allergy to kiwi fruit and severe atopic tendencies. The other four patients had been avoiding contact with rubber/latex anyway because of dermatitis or non-specific skin irritation.

\section{Effect on contraceptive care}

Gloves and condoms are the main latex hazards. Latex-free gloves were always available but latex-free condoms were sometimes in short supply. No latex-free diaphragms were available. Pills, Implanon ${ }^{\circledR}$, intrauterine devices and Mirena ${ }^{\circledR}$ are latex-free. Injected drugs remain a problem. The Trust only purchases latex-free syringes, and lidocaine for removing Implanon is in a glass vial; however, both Lignospan Special ${ }^{\circledR}$ and Scandonest ${ }^{\circledR}$ dental cartridges used for cervical blocks contain NRL, so should not be used in patients with Type I NRL allergy. Depo-Provera ${ }^{\circledR}$ has a synthetic rubber bung without NRL and was used without mishap by nine of the patients in the study despite symptoms suggesting Type I NRL allergy.

\section{Conclusions}

Patients complaining of itching and rashes following condom use usually had symptoms with other rubber/latex items and risk factors for Type I NRL allergy. They should be treated as potentially allergic to latex, as recommended by the HSE toolkit. Staff need to be aware of sources of latex in contraceptive care and have latex-free alternatives, 
since this study shows that nearly $4 \%$ of contraceptive patients may need them.

\section{Statements on funding and competing interests \\ Funding None identified. \\ Competing interests None identified.}

\section{Author's note}

The work was undertaken by a clinician with Type I NRL allergy so latex-free gloves were always available to examine patients in whom latex allergy was suspected.

\section{References}

1 Guillebaud J. Contraception: Your Questions Answered (4th edn). London, UK: Churchill Livingstone, 2003.

2 Medicines and Healthcare products Regulatory Agency. Latex Sensitisation in the Healthcare Setting (Use of Latex Gloves)

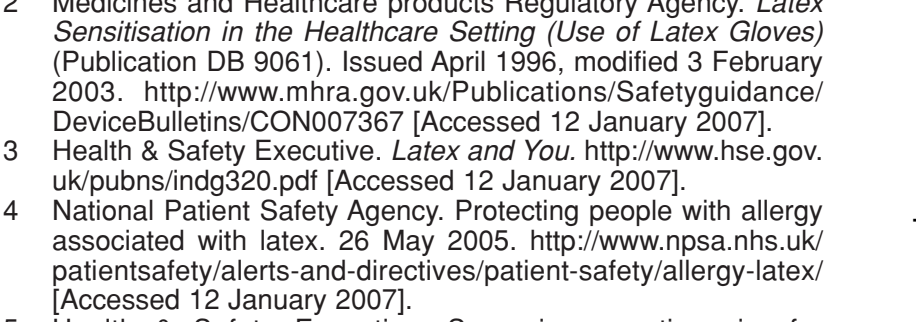

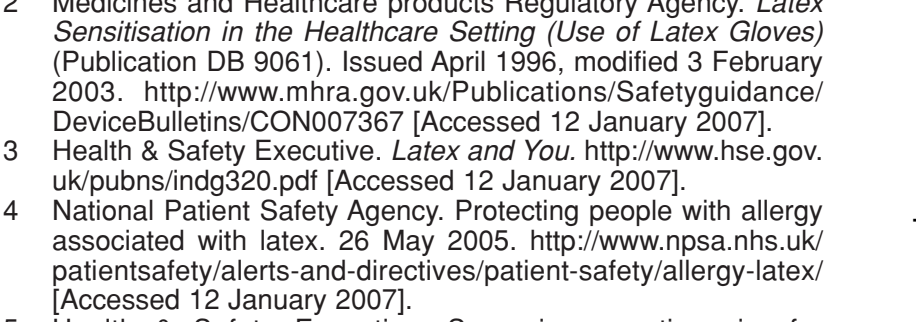

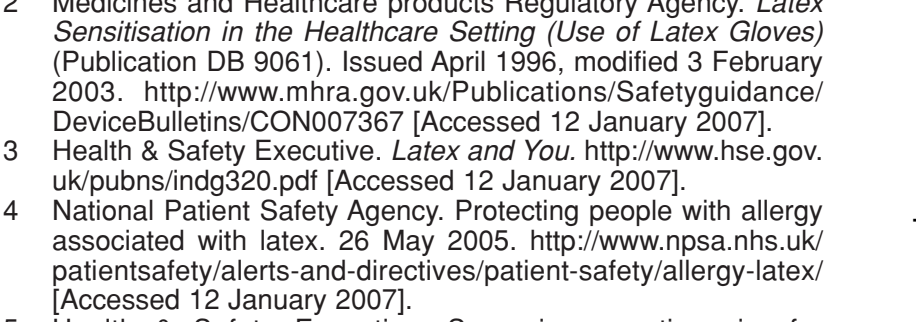

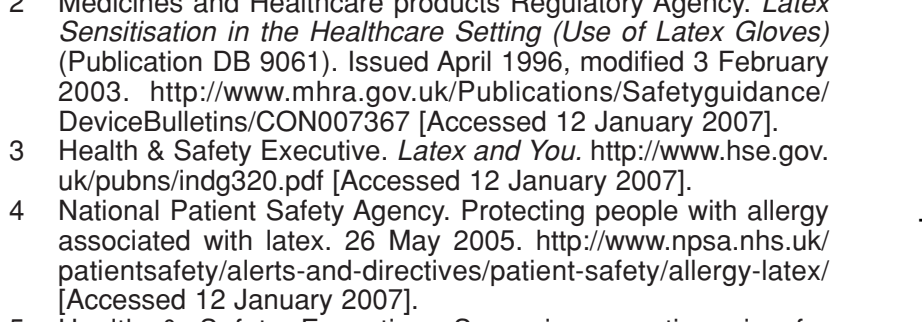

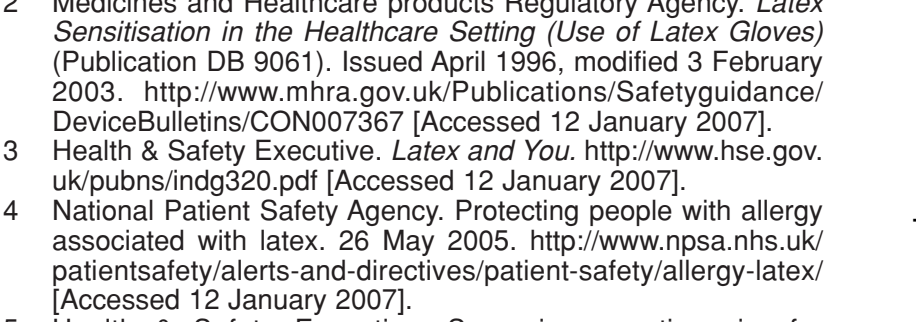

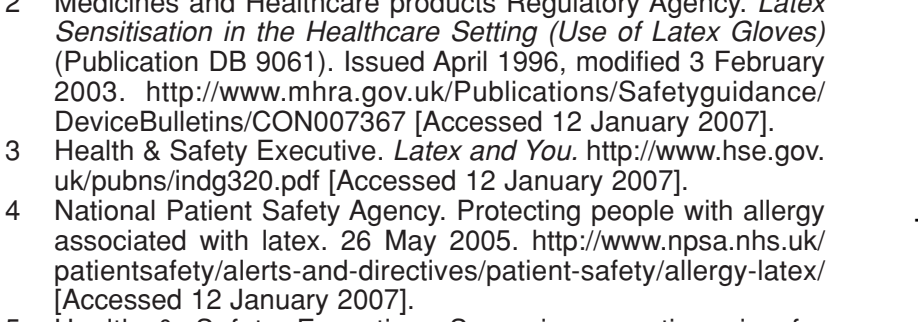

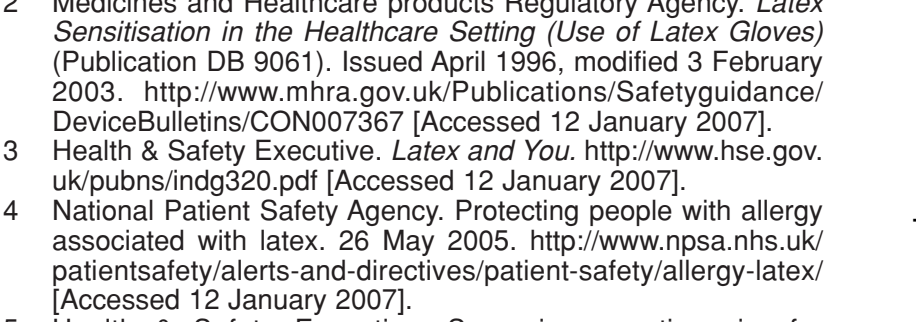

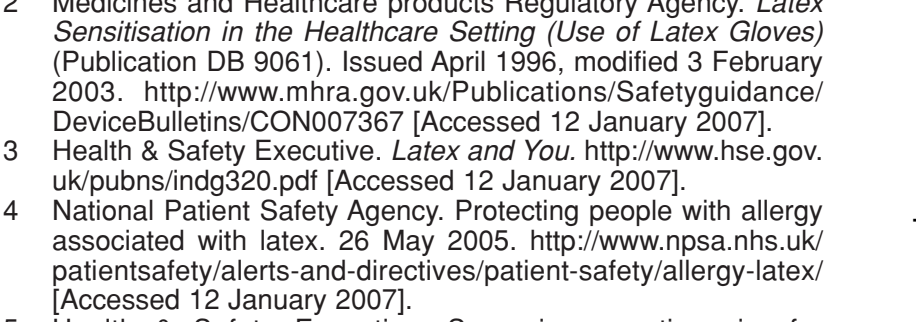

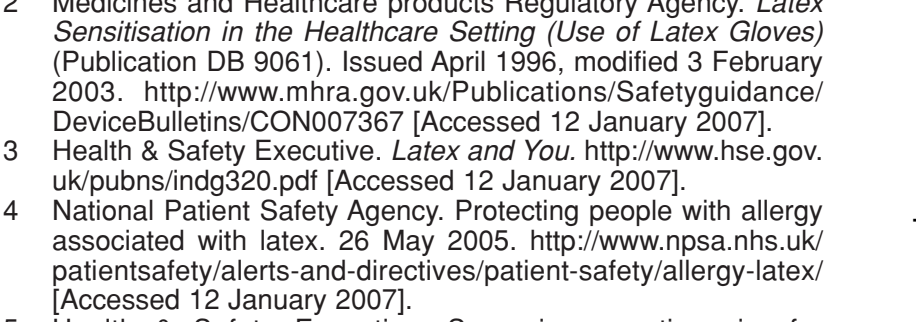

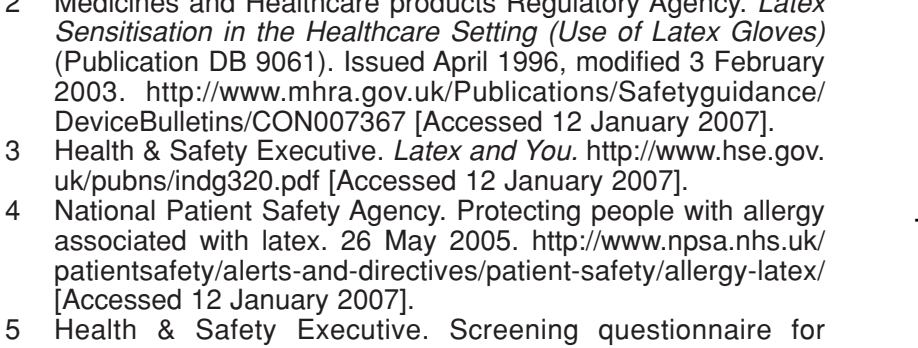
identifying NRL sensitivity. http://www.hse.gov.uk/latex/ outpatients.htm [Accessed 12 January 2007].

NEWS ROUNDUP

\section{New websites launched to help couples facing infertility}

Infertility Network UK and More To Life, national charities set up to help those suffering from infertility or facing involuntary childlessness, have launched new websites for the one in six couples facing infertility. These offer downloadable fact sheets and books to purchase in the new online shop. The websites offer a members' only forum and dedicated chatrooms, a first for More To Life users, providing a safe online community facilitated by their Online Community Organiser who is also a qualified counsellor.

Sources: www infertilitynetworkuk com and www.moretolife.co.uk

\section{New EQUATOR website}

EQUATOR is a new website that aims to provide resources for good reporting of health research. EQUATOR collates all the available guidelines covering a huge range of study designs. All the guidelines have the same aim: to help authors write clearer papers so that readers can understand the work more fully. CONSORT (for reporting of clinical trials) is probably the best known; others include MOOSE (for metaanalyses of observational studies) and STARLITE (for proposed standards for reporting of literature searches). The Public Library of Science (PloS) asks authors to consider guidelines before submitting studies.

Source: http://www.plos.org/cms/node/282

\section{Teenage sexual behaviour}

Data from almost 5000 pupils from 24 Scottish schools showed that overall, at an average age of 16 years and 1 month, $42 \%$ of girls and $33 \%$ of boys reported experience of sexual intercourse, but the rates between schools ranged widely, from $23 \%$ to $61 \%$. The results revealed that school level socioeconomic factors remain influential even after individual pupils' socioeconomic status is taken into account. This suggests that an individual who is deprived but attending a school with an affluent catchment may be discouraged from sexual activity, whilst an affluent individual attending a school with a deprived catchment may be encouraged towards earlier sexual intercourse.

The results show that how well a school is run appears to have little influence on the sexual behaviour of its pupils. Accounting for all the known predictors of sexual activity, for example parental monitoring, individual socioeconomic factors, the age of pupils, their levels of personal spending money or the proportion of their friends perceived to be having sex, the variance between schools dropped sharply. The characteristics of a school, including relationships between teachers and pupils, appearance, discipline and the school's layout were found to have only a weak impact on the rates of sexual experience.

The authors comment that "to make an impact on levels of early sexual activity and pregnancy the government would need to tackle deprivation and socio-economic problems within neighbourhoods. For instance, young women should be empowered to pursue their educational and career aspirations even when background socio-cultural factors have led them to have sex early. This may help break the cycle of deprivation for their children."

\section{Reference}

Henderson M, Butcher I, Wight D, Williamson L, Raab G. What explains between-school differences in rates of sexual experience? BMC Public Health 2008; 8(1): 53 [Epub 8 February 2008].

\section{New CEO for fpa}

Julie Bentley has recently been appointed as the fpa's new Chief Executive Officer (CEO). Julie was formerly CEO of personal safety charity, The Suzy Lamplugh Trust. More information about Julie can be found on the fpa's website where visitors can read The Quick Interview in which Julie talks candidly and answers some of the top questions asked of a new CEO at the start of their tenure with one of the country's leading sexual health charities.

\section{Source: www.fpa.org.uk}

\section{Cervical cancer care}

Analysis of data from the NHS Cervical Screening Programme reveals that fewer women need repeat cervical smears due to inadequate samples than in previous years. The introduction of liquid-based cytology (LBC) to replace conventional Pap smear tests has significantly reduced the number of inadequate tests from $7.2 \%$ in $2005 / 2006$ to $4.7 \%$ in $2006 / 2007$. Results of tests are back sooner and access to colposcopy was also faster. The full report entitled Cervical Screening Programme, England 2006-07 is available on The Information Centre website.

\section{Source: www.ic.nhs.uk/pubs/cervscreen0607}

\section{Sexual awareness in Europe}

On St Valentine's Day, a day traditionally dedicated to love and to sexual health, the European Sexual Dysfunction Alliance (ESDA) reminded everyone of the importance of sexual health as a part of overall health. Prevalence studies show that sexual health problems are very common and are often ignored, leading to a negative impact on a person's quality of life, their personal relationships and their self-esteem. ESDA is an umbrella organisation for patient support helplines across Europe. They have national websites and fact sheets on different sexual problems in different languages and these can be sent to callers who request them free of charge. ESDA helplines in France, Greece, UK, Spain and Sweden received a total of 11000 calls in 2007. Callers varied between countries, with
92.4\% of callers in France being men, compared with $75 \%$ in the UK. French male callers would wait for an average of 3 years of symptoms before calling compared with Spanish men who waited for over 4 years. Problems affecting men included erectile dysfunction and premature ejaculation. Women were troubled by reduced sexual interest and desire $50 \%$ of female UK callers). ESDA provides information, support and reassurance. A telephone advisor discusses the problem and encourages callers to consult their doctor. It is vital for the public to know that a sexual health problem is often the first sign of an important undiagnosed health problem such as diabetes, hypertension or depression. A visit to the doctor to discuss the problem is crucial as the first step to getting the right assessment, tests, treatment and follow-up.

Source: http://www.essm.org/esda/general.asp

\section{' $G$ spot' identified}

The search for the 'G spot orgasm' has led Italian researchers to seek out anatomical differences between women who claim to experience vaginal orgasms involving a G spot and those who don't. A simple test could tell you if it's time to give up the hunt, or if your partner just needs to try harder.

Researchers had already found biochemical markers relating to heightened sexual function in tissue between the vagina and urethra, where the $\mathrm{G}$ spot is said to be located. However, they had been unable to link the presence of these markers to the ability to experience a vaginal orgasm, namely an orgasm triggered by stimulation of the front vaginal wall without any simultaneous stimulation of the clitoris.

A team led by Emmanuele Jannini, at the School of Sexology at the University of L'Aquila in Italy, used vaginal ultrasound to scan the entire urethrovaginal space - the area of tissue between the vagina and urethra thought to house the G spot. ${ }^{1}$ The team scanned nine women who said they had vaginal orgasms and 11 who said they didn't. They found that tissue in the urethrovaginal space was thicker in the first group of women. The report concludes that women without any visible evidence of a $\mathrm{G}$ spot cannot have a vaginal orgasm. The urethrovaginal space is rich in blood vessels, glands, muscle fibres, nerves, and - in some women - a remnant of the embryological prostate called the Skene's glands. Some researchers have suggested that the Skene's glands are involved in triggering vaginal orgasms and, more controversially, enable a small number of women to ejaculate.

Reference

Gravina GL, Brandetti F, Martini P, Carosa E, Di Stasi SM, Morano S, et al. Measurement of the thickness of the urethrovaginal space in women with or without vaginal orgasm. J Sex Med 2008; 5: 610-618.

Reviewed by Henrietta Hughes

General Practitioner, London, UK 